\title{
Além do eu: literatura, história e memória em Teresina etc., de Antonio Candido*
}

Ligia Chiappini

$\mathrm{N}$ ão vou tratar aqui propriamente de memórias, mas do que poderíamos chamar "textosmemorialísticos" deA ntonio C andido, textos que relembram pessoas, em geral pessoas que já morreram, mas que deixaram profundas marcas na memória e cujas vidas podem ser rememoradas também pelas marcas (nem sempre fáceis de perceber) que deixaram na história, embora não necessariamente na historiografia.

$\mathrm{R}$ efiro-me a textos que começam a aparecer concomitantemente aos estudos mais propriamente literários do crítico, já nos anos de 1950, mas que proliferam de 1970 a 1990, irrompendo da memória, muitas vezes auxiliada por discreta pesquisa e que ainda hoje aparecem, quando aos 83 anos Antonio $C$ andido resolve tirar da gaveta e publicar o retrato de seu bisavô: $\mathrm{U} m$ funcionário da monarquia: ensaio sobre o segundo escalão (C andido, 2002).

Alguns desses textos já foram denominados "escritos de circunstância", por M urilo M arcondes de M oura e Antonio Arnoni Prado, a propósito do livro R ecortes (1993) em, respectivamente, "Circunstância e intersecções" (M oura, 1993) e "Significação de recortes" (Prado, 1999). Bem antes, no ensaio intitulado "A notador à margem" (1992), A ntonio A rnoni Prado escreveu sobre os perfis que $A$ ntonio $C$ andido traça de $M$ ário de $A$ ndrade $\mathrm{O}$ swald de Andrade, talvez os primeiros retratos mais significativos que pintou com palavras. E fala aí de uma" memória ensaística que se manifesta como voz à margem", na qual a "anotação de circunstância é complementar ao ato crítico" (Prado, 1992, p. 135), como também de "registros de circunstância" que
* Texto escrito para o se minário M emória e História: M etáforas da $\mathrm{Na}$ ção/ EmblemasdaN acionalidade, U niversidade La Sapienza, R oma, 29 a 31 de outubro. 
1. U m comentário crítico pioneiro e muito percuciente foi publicado no calor da hora por G alvão eLafer (1981), na resenha "Teresina - e muito mais", antecipando questões aqui tratadas e pontuadas em certos momentos deste texto. $M$ ais recentemente, Walnice N ogueira Galvão (2000) volta a reportar-se ao texto de Antonio Candido e à sua personagem, em artigo intitulado originalmente"A militanteTeresina", que acabou sendo publicado como "A primeira paisana".

2. Essas informações me foram fornecidasem conversa com Antonio $C$ andido, em setembro de 2001 e reconfirmadas por telefone em janeiro de 2002. D os três, apenas o retrato do fazendeiro, chamado Pio Lourenço Correa, ainda não foi escrito.

3. São também referência os retratos de outros intelectuais: de M ário e 0 swald de Andrade (em 0 observador literário, 1959), retomados em $R$ ecortes (1993), mas, antes, em Vários escritos (1970); de Cruz Costa e
[...] aparecem quase sempre em formulações da memória que numa primeira leitura não revelam todo o seu peso, quer dizer: lidos, ficam no ar até constatarmos que não podem mais ser preteridos, o que nos obriga a relê-los, para nos darmos conta do seu alcance (I dem, 1992, p. 136).

A um desses retratos especialmente me proponho a voltar, como convite à releitura no sentido em que Arnoni sugere, já que o texto merece um estudo mais detal hado ${ }^{1}$.T rata- se do retrato deTeresina,Teresa $\mathrm{M}$ aria $\mathrm{C}$ arini, a anarquista italiana, amiga da mãe deA ntonio $\mathrm{C}$ andido (e, depois, dele mesmo), que nasceu em 1883 naA Ideia de Fontanellato ("recente Província de R eggio-Emilia do recente $\mathrm{R}$ eino da Itália", nas palavras de C andido), cresceu, casou e imigrou para o Brasil, vivendo inicialmente em São Paulo e depois, já separada do marido, boa parte da vida em Poços de C aldas, onde morreu em 1952.

Segundo informações do próprio crítico, esse texto, publicado em 1956 (em jornal) e em 1959 (em livro), depois, ampliado e republicado na década de 1980 no livro Teresina, etc, deveria compor uma trilogia, da qual constariam o retrato de seu bisavô, mencionado acima, funcionário do segundo escalão, o retrato de um fazendeiro, tio de Gilda de M ello e Souza, e o retrato deTeresina, uma anarquista e socialista do contra².

M eu propósito aqui, como já disse, é comentar o texto "Teresina" ${ }^{\text {, dentro }}$ do tema geral das relações entre história, memória e literatura, indagando um pouco mais sobre como se constrói um texto que, nos termos ainda de Arnoni Prado, referindo-se aos ensaios de R ecortes, é "depoimento sem ser memória, memória sem ser ensaio, anotação meticulosa sem ser texto de análise" e valoriza a" novidade da mescla" como "coisa rara na crítica" (Prado, 1993). Para Arnoni, R ecortes escapa à classificação. 0 mesmo podemos dizer tanto do texto "Teresina", como do próprio livro, Teresina etc. 0 ensaio ocupa as primeiras oitenta páginas, e a segunda parte, com as demais noventa páginas, distribui-se em diversos pequenos textos: sobre João do R io; resenhas de livros como o de M aria R ita Galvão, sobre a companhia de cinema Vera Cruz ou o de C hasin, sobre o integralismo; o famoso texto sobre R aízes do Brasil; um depoimento sobre o grupo e a revista Clima; o texto também muito conhecido sobre o congresso dos escritores em 1945 e um comentário do filme Inquérito sobre um ádadão acima de qualquer suspeita, de Elio Petri, que, na verdade, quer falar da repressão militar para desvendar a sua verdade: "A verdade da repressão".

Essa segunda parte talvez seja o etc., mas este também compõe a biografia deTeresina, como veremos, na medida em que no seu retrato se tecem outros fios da memória de homens, grupos, cenários, problemas, conflitos e ideais dos dois lados do oceano. 
Trata-se de uma produção fragmentária que nem por isso deixa de ser coerente. Pelo contrário, ressalta a coerência não apenas entre esses textos fragmentários, como também com a obra toda do crítico, com seus ensaios de crítica literária, com algumas noções recorrentes, mas, sobretudo, com uma atitude crítica rigorosa e compreensiva, que procura incessantemente fazer justiça aos textos e aos seus autores, mantendo o ponto de vista de um crítico ferrenhamente socialista sem deixar de considerar os dois gumes das pessoas, de seus escritos e da própria história em que eles se inserem e que, em parte, contam. 0 texto "Teresina" foi pioneiro, indo além da rememoração da amiga, para, por meio dessa lembrança, fazer toda a avaliação de uma época. U $m$ texto escrito com coração e lembrança, levando a análise a domínios inexplorados.

$\mathrm{N}$ ovidade talvez maior aqui é que isso se faz a partir da vida obscura de uma mulher que merecera a atenção do crítico já conhecido e famoso, no mesmo ano em que ele publicara sua grande obra, A formação da literatura brasileira (1959), conforme assinalou Barbosa (1986, p. 101).

\section{A figura e 0 contexto}

Passemos de imediato a uma breve descrição desse ensaio-memória, nas suas duas versões. 0 texto foi publicado em um periódico, em 1956, quatro anos depois da morte da amiga. Três anos mais tarde foi republicado sem maiores modificações em 0 observador literário, de 1959, onde já aparece ao lado de outros dois retratos, que também serão retomados e republicados pelo autor: "Lembrança de M ário de Andrade" e "O swaldV Viajante" ${ }^{4}$.

Essa primeira versão deu origem à versão aumentada de 1980.0 texto de 1959 tem apenas seis páginas e estrutura-se linearmente nos seguintes fragmentos sem subtítulos:

- O rigem de Teresina, data e lugar de nascimento, família.

- M orte do pai e casamento com Guido R occhi, músico.

- Vinda para o Brasil do casal; vida em Santos e São Paulo; separação e mudança (dela e, depois, dele) para Poços de C aldas.

- Descrição física e moral deTeresina.

- M odo de vida e descrição da sua casa, móveis e gatos.

- M odo de ser; atitude igualitária e gestos que o comprovam; temperamento.

- Inspirações revolucionárias-leituras; militância.

- Velhice, doença e morte.

A pesar da brevidade, o estilo já volta e meia alça o vôo da literatura, na criação da personagem e dos ambientes.
R ui Coelho; ostextosde homenagem aosmortos, como "As três bandeiras", sobre D arcy R ibeiro, publicado na $\mathrm{F}$ olha de São Paulo, quando de sua morte; a entrevista recente sobre Érico Veríssimo publicada em Pesavento et al. (2001); e a maior parte dostextos publicados em $R$ ecortes e em Te resina etc $E$, ainda, ostextos so bre biografia e autobiografia, como o que escreveem A educação pela noite (1987), "Poesia e fiç̧ão na autobiografia", falando de Pedro $\mathrm{N}$ ava.

4. Ver "Estouro e libertação" , "O swaldo viajante", "D igressão sentimental sobre $\mathrm{O}$ swaldo de Andrade" (C andido, 1970, pp. 33-92). 
A nova versão vai aprofundar esse tom e desenvolver os mesmos elementos, num conjunto não apenas ampliado (67 páginas das quais doze de ilustrações, fotografias deTeresina, sua família e seus amigos), mas também estruturalmente transformado.

Esse ensaio de 1980 começa com o capítulo denominado "C rônica inicial", subdividido em três subcapítulos: "Fontanellato", "M úsica e Brasil" e "O casal mal afinado", que - salvo um salto temporal para a década de 40 do século XX no meio e uma volta ao final do século XIX no fim - também vai quase linearmente da infância na aldeia e no castelo italiano, onde trabal hava o pai deTeresina, ao casamento dela com o músico R occhi e a mudança do casal para o Brasil, chegando à separação e à transferência definitiva para Poços de $\mathrm{C}$ aldas, a vida e a morte da personagem nessa pequena cidade. $\mathrm{N} O$ capítulo 2, intitulado "O ser e as convicções", C andido reserva um largo espaço para desdobrar o que fora dois ou três parágrafos no texto de 1959: 0 retrato físico e espiritual deTeresina, bem como a narrativa de sua militância contra o fascismo e a favor do socialismo. Esse capítulo subdivide-se em quatro subcapítulos intitulados: "R etrato falado", "Ser socialista", "Écrason l'infame", "M ilitância e fascismo".

0 terceiro e último capítulo, "O s outros", parece fugir da personagem, enfocando-a indiretamente por meio de seus amigos e da polêmica relação que ela mantinha com eles, pelo julgamento severo de suas opções políticas. Esse capítulo também se subdivide em vários subcapítulos e é ilustrado por sugestivas fotos de Teresina, sua família e seus amigos. 0 s títulos desses sete subcapítulos são: "Visitantes", "C ultura paralela", "Bertolotti e o Avanti!", "Picarollo moderato assai", "R ossini: herói (e vilão) de dois mundos", "De Ambris oscilante", "O peso e a medida".

Se o segundo capítulo concentra-se no ser deTeresina e em sua forma de conceber e viver a militância pelo socialismo, o terceiro expande o leque de interesse e de personagens para voltar a concentrar-se nela no final, ou, mais especificamente, no peso e na medida com que ela "re-escolhe" os amigos, depois do trauma fascista, mantendo- os ou borrando- os do coração e da memória, o que se metaforiza economicamente na descrição de Antonio $\mathrm{C}$ andido pelo retrato do amigo que se distanciou do fascismo em tempo, e que ela conservou na parede, em oposição ao bilhete feroz com que encerrou sua

5. G alvão e Lafer (1981, p. 167) sublinham no texto "Teresina" o "poder de iluminação e esclarecimento do contexto em que vivemos". amizade com um amigo liberal, que se aderiu ao fascismo. D uas mensagens simbólicas, cujo sentido, para a vida de Teresina e para o entendimento do velho socialismo ítalo- paulista (capítulo importante da história do B rasil e do socialismo em geral), o intérprete sensível desvelou ${ }^{5}$.

Como centro do ensaio pode-se ler o subcapítulo "Ser socialista", no qual, depois de comparar Teresina a Louise M ichel,Vera Z asulitch ou R osa 
Luxemburgo - que pertenceriam "a certa categoria de santidade da revolução" -, diz A ntonio C andido: "N ão foi grande militante e não marcou 0 seu tempo, nem mesmo na escala modesta dos companheiros de luta em São Paulo, nos primeiros anos do século" (C andido, 1980, p. 28).

Isso parece contrariar o paralelo acima, pois demonstra que, ao contrário daquel as mulheres notáveis, cuja existência não pode ser ignorada pela historiografia, Teresina não passou de uma obscura intelectual socialista de Poços de $\mathrm{C}$ aldas. Entretanto, prossegue Antonio $\mathrm{C}$ andido:

M as foi excepcional pela maneira por que vivia em cada instante as suas idéias, sentindo e praticando em relação ao próximo a fraternidade igualitária que elas pressupõem, e que permite fazer da vida uma tentativa de superar o egoísmo, 0 preconceito, 0 gosto da dominação, 0 apego aos bens materiais, a reverência pelos apoios grotescos da vaidade (Idem, ibidem).

Assim, o anonimato acaba sendo um critério em favor deTeresina, que se mantém social ista na teoria e na prática mesmo sem pertencer a uma organização que a motive a tanto. $D$ aí a necessidade de rememorar. Porque lembrar dela é tirá-la desse anonimato e transformá-la em exemplo de ser socialista. Ser aqui é verbo e substantivo: para ser socialista, para ser classificada como tal, é necessário al go mais do que pertencer a um partido ou militar externamente, é necessário moldar-se diariamente como ser, para o que não basta agir e pensar, mas é preciso integrar nisso coração, cabeça e estômago, para usar uma metáfora do escritor português $C$ amilo $C$ astelo $B$ ranco. É isso que se explicita, quando Antonio $\mathrm{C}$ andido conclui:

Teresina ilustrava de maneira admirável o que é "ser socialista" - aparentemente um paradoxo, porque em geral focalizamos no socialismo o pensar e 0 agir, enquadrados em organizações ou produzindo atose obras especificamente políticos. Isso faz esquecer que existem também os sentimentos e a ética de um socialista. Ela passou a maior parte da vida fora da ação partidária, vivendo os últimos quarenta anos quase isolada politicamente numa cidade pequena. Talvez esta circunstância haja estimulado a densa precipitação de um modo de ser, segundo o qual a revolução se torna concepção integral, iluminando e condicionando o pormenor dos atos e a tonalidade da vida (Idem, ibidem).

Ainda nesse capítulo, central em todos os sentidos, para entender por que Antonio $\mathrm{C}$ andido decidiu voltar ao retrato de Teresina, ampliando-o e aprofundando-o, escavando mais fundo na memória pessoal e na que se depositou em arquivos e livros - cartas, testemunhos e fotos (pois fica evidente 
que aqui o texto se ampliou com pesquisa) - , mais dois elementos merecem ser destacados. 0 primeiro é 0 aparente ecletismo deTeresina, que o autor lê como perspectiva integradora, em torno de uma questão-chave, a cercar por todos os meios, ao alcance de quem a pensa e vive. Trata-se da própria concepção de socialismo como amálgama indissolúvel entre teoria e prática. Assim, depois de dizer que ela "englobava fraternalmente as ideologias do contra", de R ousseau a Lênin, "absorvendo dois séculos de pensamento libertador e outras modalidades que reinterpretava conforme este", C andido ilustra isso brilhantemente com este parágrafo:

Argumentava contra o fanatismo com o M aomé deVoltaire, pela emancipação feminina com M ary Shelley, contra a miséria com Z ola, pela fraternidade com Victor H ugo, contra a guerra com a Baronesa de Suttner, pela união operária com Proudhon, contra o capitalismo com M arx, pela violência com Bakunine e pela cooperação com K ropotkine, contra D eus com Sébastien Faure, pela pureza da vocação com R omain R olland (Idem, ibidem).

A essas leituras somavam-se, segundo ele, princípios do sonho socialista: "os da revolução francesa em 89, da revolução de 48, da comuna de Paris, dos mártires de $\mathrm{C}$ hicago, das greves, dos atentados niilistas, da revolução russa" (C andido, 1980, p. 29).

Isso, que superficialmente poderíamos ver como uma espécie de "samba do crioulo doido", sobretudo dentro do rigor teórico que o cientificismo de nossos tempos a partir do estruturalismo nos acostumou, pode definir uma original tentativa de construir um peculiar anarco-socialismo, para o qual "as aspirações veementes à libertação total do homem por meio da igualdade econômica e os milagres do saber eram uma força mais viva do que o desejo de sistematização teórica" (Idem, ibidem).

A essa altura, Antonio $C$ andido atinge, por meio do retrato, os limites do auto-retrato, utilizando a mediação do " pioneiro socialista $\mathrm{O}$ svaldo $\mathrm{G}$ nocchiViani" que, segundo Turati, citado por Candido,

[...] era quase isento de necessidades materiais, al heio a toda vaidade pessoal mesquinha, profunda e constitucionalmente otimista, cândido como uma menina [...]. D e M azzini tinha rejeitado a filosofia religiosa [...] e as preocupações patrióticas dominantes. M as do pensamento mazziniano ficara-Ihe intacta a essência idealista, mística e sentimental, para a qual a questão social, em vez de ser um fato peculiarmente econômico e histórico, é o conjunto de todas as questões ideais que interessam à humanidade; é a conseqüência do pensamento humano que se desenvolve aos poucos, e para o qual há uma questão cósmica [...], uma questão 
educacional, familiar, da arte, etc.; e também, entre outras, uma questão econômica e uma questão operária, a das relações entre capital e trabalho; mas todas no mesmo nível, todas, diríamos, vinculadas entre si horizontalmente, mais do que geneticamente [...]. D aí o fato do materialismo econômico, alma e fundamento do pensamento marxista, Ihe parecer uma teoria entre outras, uma verdade parcial entre as muitas verdades das quais sé tecido o estofo socialista; e não como a chave da evolução da sociedade (C andido, 1980, p. 30) .

0 segundo aspecto que também pode nos levar a ler no retrato um autoretrato é a defesa do sonho socialista, também aqui mediada por outra voz, neste caso, a da própria Teresina, materializada numa notação transcrita de um caderno vasculhado por Antonio $C$ andido. Pensando em outras falas, escritos e atitudes dele (como a repetição enfática, muitas vezes, da frase: "eu sou um otimista por convicção e natureza"), podemos atribuir a essa parte o título de: "O dever do otimismo ou para além do desencanto, a defesa do sonho". Eis a nota deTeresina:

O s erros dos outros devem indicar o melhor caminho para nós seguirmos e... sonharmos...V ive-se melhor sonhando! O s sonhos e os ideais alegram a vida e a prolongam, porque nos mantêm fortes e esperançosos de um futuro mais belo. Entre eles haverá algum irrealizável... uma utopia... M as que importa? A H istória da H umanidade diz que o culto de um ideal e de uma quimera é o elixir da longa vida, a pedra filosofal, em virtude dos quais um povo não morre. D epois de nós, al guém verá realizado o nosso sonho.Teremostido o mérito de haver contribuído para essa realização (I dem, pp. 30-31).

A o relermos hoje essa citação de 1935, retomada em 1980 - quando se abria a chamada década perdida, quando se sepultavam os sonhos dos anos de 1960 e 1970 no Brasil e no mundo - , e ao pensarmos que o homem que a transcreveu tem 83 anos e ainda sonha esse sonho e ainda age para torná-lo realidade - apesar de todas as decepções sofridas com sucessos que Teresina não chegou a ver, como os horrores do stalinismo e os horrores das "guerras ditas humanitáriase santas" dosnossos dias-, sentimos-nos com obrigação de continuar sonhando e lutando contra a maré do tacanho pragmatismo dos donos do mundo e contra os riscos que cercam hoje o pensamento de es querda, dividido entre a perplexidade paralisante e a reiteração de um dogmatismo no mínimo ultrapassado.

D epois de narrar a morte deTeresina, enclausurada num quarto de hospital e seu enterro emoldurado pelos versos de Leopardi ("Erta la fronte... / E renitente al fato"), no final do segundo capítulo,A ntonio $C$ andido a ressuscita
6. A mesma semelhança entre retrato e auto-retrato é assinalada, em relação a R ecortes, num texto inédito deAndréa dos Santos, "A notaçõessobre recortes", preparado para a discussão do C entro Ángel R amaem 1 deabril de 1997, como parte do projeto Ángel $\mathrm{R}$ ama e Antonio Candido. Diz ela: "Ao pintar o retrato de terceirose dar sua opinião sobre assuntos polêmicos ou de literatura, vemos esculpida a própria figura de C andido" (Arquivos do Centro Ángel $\mathrm{R}$ ama, da U niversidade de São Paulo, p. 2). 
no último capítulo, "O soutros", na figura das pessoas com quem conviveu, a começar por sua própria mãe e por ele mesmo. A narrativa centra-se num desfile de amigosque o autor conheceu durante sua convivência com a biografada entre 1931 e 1951.0 retrato deTeresina então se multiplica ou dá ensejo a outros retratos, mesmo que apenas esboçados, vitais, como o do professor português, atarracado e explosivo, também anarquista, Edgard Leuenroth, ou o do advogado, doutor Badalassi. Em "C ultura paralela", prolonga se o retrato, com osamigosde São Paulo, num momento de germinação esperançosa do socialis mo - entre o fim do século e a Primeira G uerra. R egistra-se, então, a presença de visitantes estrangeiros conhecidos, como Enrico Ferri, (1908) e G uglielmo Ferrero (1907). De passagem, A ntonio C andido critica o dogmatismo da esquerda em arte, o que faz de modo notável e atual.

Era o tempo em que o socialismo e sobretudo o anarquismo pressupunham uma crença muito forte na capacidade revolucionária (transformadora e humanizadora) do saber e da arte. Q uanto à literatura, isso ocorria no sentido do que se poderia chamar uma cultura dos conteúdos, inteiramente voltada para a mensagem explícita das obras, sem preocupação específica pelo caráter avançado ou não daforma, que poderia inclusive ser a mais acadêmica. É o problema da mistura de intenção política avançada e gosto atrasado, freqüente no universo cultural das esquerdas. Isso porque as pedras de toque eram 0 ataque à burguesia, a descrição da vida operária, os sentimentos humanitários, a posição anti-religiosa, a solidariedade com o pobre, etc. - considerados como condição que de ideologicamente relevante passava a suficiente (Idem, p. 48).

A propósito dos amigos, a memória expande-se para traçar um clima de época dos encontros, leituras e hábitos dos anarquistas e socialistas (I dem, p. 49), destacando a importância da literatura e das artes. $\mathrm{N}$ o final, uma síntese que liga o particular ao geral:"O samigos deTeresina tiveram papel importante nas lutas políticas e nas vibrações culturais daquele tempo, como uma espécie de ala brasileira informal do Partido Socialista Italiano; e ela com eles" (Idem, p. 51).

0 método

Do ponto de vista metodológico, os textos memorialísticos de Antonio $\mathrm{C}$ andido acabam praticando aquilo que ele, ao falar de Pedro $\mathrm{N}$ ava, louva:

N os seus dois livros a autobiografia desiza para a biografia, que por sua vez tem aberturas para a história de grupo, da qual emerge em plano mais largo a visão da sociedade, traduzida finalmente numa certavisão do mundo (C andido, 1987, p. 61). 
Também o que diz a seguir revela algo sobre o seu próprio método:

0 motivo dessa transfiguração do dado básico é sem dúvida o tratamento nitida mente ficcional, que dá ares de invenção à realidade, transpondo para lá deles mesmos o detalhe e o contingente, o individual e o particular (Idem, ibidem).

Eu diria que seu tom ensaístico dá aos retratos como o de Teresina uma dimensão quase ficcional, porque, como ele mesmo diz, um traço da literatura de ficção seria

[...] a relação reverśivel Particular-U niversal sem o que não há eficiência do texto e onde os dois termos possuem igual importância, sendo ela que garante a validade da outra relação que também está presente nestes livros e também é necessária para a sua eficácia: $R$ ealidade - invenção (Idem, p. 63).

Esse mesmo método supõe a circulação permanente entre o detalhe e 0 todo, como na análise do texto literário. U m método que ele descreve como 0 de Proust em E m busca do tempo perdido.Vejamos como o concebe no pequeno texto "R ealidade e realismo (via M arcel Proust)" (C andido, 1993, pp. 123-129):

A través dos seus textos verifica-se que o enfoque literário do mundo interior ou exterior ganha sentido quando a especificidade do detalhe se integra numa visada generalizada que o transfigura. 0 detalhe funciona então como tecla que, ao lado das outras, permite modular a linha expressiva da representação ficcional.

[...] o narrador enxerga, num nível além dos detalhes externos, uma semiprofundidade (como diz Proust) caracterizada pela unificação, não a soma dos pormenores. $N$ esse nível os detalhes deixam de ser parciais e isolados para exprimirem uma totalidade, una e coerente, que serve de base verdadeira da interpretação (Idem, pp. 125-126).

Esse método amarra de modo peculiar espaço e tempo:

[...] a ligação entre objetos, lugares e pessoas não ocorre apenas num momento; ela se desdobra no tempo. [...] Surge então o paradoxo: ver as coisas no tempo é vê-las de modos diversos, em várias etapas, portanto, é atingir um maior grau de generalidade, que define a permanência (relativa) da estrutura sob o processo que a constitui. D e tal forma que o caso singular ganha certa generalidade acima do tempo que o gerou e do qual emerge. Estrutura e processo, estático e dinâmico se unem na síntese de uma visão integrativa. 
[...] Em tudo isso se destaca a dimensão temporal, deixando ver a permanência do gênero sob a mudança das coisas, dos atos, das pessoas, e mostrando também que a narrativa ficcional é capaz de focalizar simultaneamente a estrutura e o processo (Idem, pp. 128-129).

A atualidade desse método e dessa concepção de memória e história se faz mais evidente quando a aproximamos de recentes observações de historiadores preocupados com a memória de sentimentose ressentimentos. $R$ efiro-me aos autores do livro M emória/ (res)sentimento: indagaçoes sobre uma questão sensível, do qual destaco estes trechos, de autoria de Jacy Alves de Seixas:

Não é, sem dúvida, fortuito que a revalorização da temática e das práticas de memória date precisamente das duas últimas décadas, "coincidindo" com acontecimentoshistóricos espetaculares (a implosão daU R SS, a queda do muro de Berlim, a explosão da ex-luguslávia, os conflitos étnicos e religiosos que irrompem de uma forma política impensável, a força da massificação e do "consentimento sem consentimento", obtidos pelo fenômeno da globalização [...]), que nos recolocam com ímpeto em face do passado experimentado como vencedor ao longo deste denso século XX, de nossa própria identidade, em face dos outros, da sociedade onde nos inserimos, em face de nossos sonhos e projetos de futuro (Alves de Seixas, 2001, p. 52).

O utras citações desse livro permitem-nos aproximar o trabalho com a memória em Antonio $\mathrm{C}$ andido e o que buscam alguns historiadores hoje:

Memórias que podem atuar como advertência e rememoração de derrotas nas quais a imagem dos vencidos assume a frente de cenários em ruínas (D e D ecca), mas que também encontram lugar na afirmação positiva do direito à cidadania por pessoas que, pela condição social e/ ou idade cronológica, deveriam se reconhecer a um não-lugar (P. Salles 0 liveira), ou que, por circunstâncias ocasionais da vida privada, vêem-Ihe recusado o lugar privilegiado da cidadania (Borges) (Bresciani e N axara, 2001, pp. 11-12).

Antonio C andido também anda na contra-mão da comemoração, sondando como podem contribuir para a história da humanidade aqueles que ficaram fora dela, no anonimato. E principalmente aquelas (lembrando que os estudosfeministas no Brasil mal começavam na época), em relação aose às quais o crítico parece afirmar "o direito e o dever da memória".

Distinguindo memória- ação, memória afetiva e memória-conhecimento, PierreA nsart (2001) insiste em que a história se detém na memória voluntária 
e que as novas tendências tentam trabal har com a memória involuntária, à maneira de $M$ arcel Proust. Daí podemos extrair maisalgunselementos para entender o método deAntonio C andido em "Teresina". D iz Jacy A lves de Seixas:

Para Proust, igualmente, a memória voluntária não é nada além da anódina “memória dos fatos", representando na realidade um obstáculo à expressão da verdadeira memória. Estima que é necessário, antes de maisnada, "romper com todas as nossas forças o gelo do hábito", levantar o "véu pesado do hábito" (hábito imbecilizante que durante todo o curso de nossa vida nos oculta mais ou menos todo 0 universo) (2001, pp. 45-46).

Ao contrário, a memória espontânea ou involuntária seria feita de "imagens que aparecem e desaparecem independentemente de nossa vontade e revelar-se-ia por "lampejos bruscos" (Idem, p. 46). Instável e descontínua, para Proust, "supõe as lacunas e constrói-se com elas. N ão soma nem subtrai, mas condensa" (Idem, p. 47). Toda memória involuntária viria "carregada de afetividade", enquanto a H istória, que trabalharia com a memória voluntária, excluiria sistematicamente "a faceta involuntária e afetiva inerente à memória" (Idem, ibidem).

Isso implica também uma nova relação entre passado e presente: "N ada mais do que um momento do passado? M uito mais, talvez; alguma coisa que, ao mesmo tempo comum ao passado e ao presente, é mais essencial do que ambos" (Proust apud Alves de Seixas, 2001, p. 49).

Há semelhanças dessa memória involuntária com o método de A ntonio C andido, mas ele não é um romancista e sabe disso. Portanto, nele se associam racionalidade e afetividade, memória voluntária e involuntária. $\mathrm{N}$ essa combinação integram-se as dimensões ética, política e epistemológica. Enquanto os historiadores falam em crise das utopias racionais e frenesi da memória, em Antonio $C$ andido podemos falar de memória sem frenesi e em permanência calma da razão que não impede a condensação, pelo charme afetivo e as tonalidades emocionais?.

"Lembramos menos para conhecer do que para agir", sublinham os his toriadores citados. $\mathrm{N}$ essa perspectiva, a memória "é menos um entender 0 passado do que um agir, impossibilitando, portanto, cogitar-se de uma memória desinteressada, voltada para o conhecimento puro e descompromissado do passado" (Alves de Seixas, 2001, p. 53). M as o destino prático da memória, sublinhado por Bergson, não quer dizer que, para agir, não tenhamos de pensar, conhecer, e que conhecer não tenha uma função política e prática também. Pensar-agir-pensar... Em A ntonio C andido, essa é a cadeia da práxis. A função ética da memória não se desvencilha tampouco nele da função
7. M ais uma vez, Galvão e Lafer (1981, p. 167) foram pioneiros ao caracterizar a concepção de "ser socialista" de Antonio Candido, intérprete das "convinções" deTeresina, como não apenas uma questão de pensamento e ação, mas antes de mais nada de sentimento e ética. 
8. Galvão e Lafer (1981, p. 167) identificam aqui, como em outras obras de Antonio Candido, "uma visão simultânea do verso e do reverso, do texto e do contexto". cognitiva. Pelo contrário. Já os historiadores, entusiasmados com Proust, propõem: atualizar a memória agindo. A ntonio $\mathrm{C}$ andido diria: mas também conhecendo e dando a conhecer.

R ememorarTeresina e seus amigos tem uma função afetiva, ética e política, mas também pedagógica: ensinar a arte da militância, radical e compreensiva e, sobretudo, como coerente combinação de teoria e prática. Por isso é fundamental que essa lembrança tenha aquilo que A ntonio $C$ andido identifica como um traço marcante na obra de C aio Prado Jr.: "a força do concreto". D aí a atenção aos detalhes, que vão dosolhos azuis deTeresina à sua aparência fora de moda; da sua casa repleta de objetos que assinalavam a passagem do tempo, das flores e dos temperos, aos gatos que amava e às unhinhas e bigodinhos deles, que colecionava. Da importância desses detalhes para o retrato que os transcende, nos fala o próprio A ntonio C andido:

C ontadas assim essas coisas parecem pitorescas e nada mais. $\mathrm{N}$ a verdade eram marcas de uma personalidade extraordinária, cheia de inquietude, ardor e bravura, fremindo de inteligência e generosidade (1980, p. 25).

Além dos detalhes que constroem a figura de Teresina e por meio dela toda uma atmosfera inerente a grupos ítalo-brasileiros, cuja atuação faz parte dahistória mais geral do anarquismo, do socialismo e do fascismo brasileiro e italiano, o discurso de Antonio $C$ andido se tece de antíteses, porque sempre está a pesar os dois gumes das pessoas, dos grupos, dos movimentos sociais e políticos, como costuma fazer quando se ocupa de textos literários?.

A tensão, que o crítico de literatura está sempre a identificar nos poemas, contose romances que analisa, entranha seus retratos. A começar pela própria Teresina, cuja metáfora śntese é a combinação dialética entre o castelo e a aldeia, desdobrando-se nas o posições seguintes: camponeses e nobres, senhores grã-finose mendigos, concertos de música clássica e sessões de cultura popular, condes e povo miúdo, pobres e ricos, salão e cozinha, mulher do presidente da R epública eT io Pedrinho, preto velho rachador de lenha, convidados por ela para almoçar lado a lado em sua casa.

M as também na descrição do seu temperamento vulcânico voltam as tensões: requinte e franqueza, capaz de invectiva e carícia, de sonho e euforia, por um lado, de desânimo e frustração, por outro; pranto e riso, sociabilidade e desconfiança, dividida entre um ateísmo intransigente e a convicção quase mística de que o sangue dos mártires era semente para a colheita do socialismo.

Socialismo é palavra-chave.As oposições todas integram-se no texto numa oposição maior que parece ser a sua mais alta motivação encarnada em Tere- 
sina, que a metaforiza: fascismo versus socialismo. Essa tensão também se desdobra em antíteses várias, tais como: batuta e espada, Toscanini e M ussolini, para concentrar-se em dois companheiros da luta anarquista: R ossini e De A mbris, os dois amigos que se envolveram com o fascismo, desdobrados, por sua vez, em duas imagens que 0 autor antecipa como quem não quer nada e que, no final, retornam, transformadas num emblema do juízo crítico de Teresina: o bilhete curto e grosso que ela dirige ao ex-amigo radical que se conservou fascista até o fim - "R ossini, sei um cane" - e o retrato conservado na parede da sala do amigo liberal que dele se afastou em tempo: D eA mbris.

A trajetória desses dois homens dá margem para Antonio $\mathrm{C}$ andido fazer uma reflexão política do maior interesse, que só é possível ser feita por quem sistematicamente busca aliar radicalidade política à compreensão humana. $R$ efiro-me ao que ele chama "os equívocos que o fascismo nascente podia suscitar num militante de esquerda", sendo confundido por muitos esquerdistas com "certa potencialidade socialista" com "elementos populares apreciáveis" (Idem, 1980, p. 65).

0 texto acaba com um convite para pensar um paradox $0^{9}$ que é 0 fato de militantes sindicalistas radicais terem aderido ao fascismo, enquanto reformistas moderados terem sido contrários a ele. M as isso, que poderia parecer a defesa dos últimos e a condenação dos primeiros, é novamente revirado de cabeça para baixo, porque o raciocínio e a sensibilidade acurados não permitem simplificações anacrônicas, como o próprio autor reconhece: "Vendo a coisa de hoje é fácil censurar e mostrar o que estava certo" (Idem, ibidem).

$R$ ecusando 0 anacronismo e pondo-se na perspectiva da época, 0 autor procura entender a posição que resiste ao fascismo como fruto do muito de liberalismo que havia no reformismo de uma reação de tipo liberal "em face duma espécie de socialismo heterodoxo e meio selvagem (como podia parecer inicialmente o fascismo), que ameaçava desmontar as regras da rotina parlamentar" (I dem, ibidem).

Por outro lado, se aí desmistifica a fama de coerência socialista que esses liberais ganharam a posteriori, $\mathrm{C}$ andido interpreta a adesão dos socialistas revolucionários ao fascismo como decorrência de sua avidez de ação, da des confiança do reformismo quase liberal e do entusiasmo "pela retórica do populismo fascista", que aparecia como "produto de uma ala socialista radical" (Idem, p. 80).

E é com o paradoxo que conclui essa reflexão: "Assim, pode-se supor que foi talvez porque professavam um socialismo ativo e exigente que muitos, paradoxalmente, embarcaram na canoa sinistra" (Idem, ibidem).

A frase revela uma constante do texto: um pensamento dialético e rigoroso, aliado a um humanismo compreensivo, em que a memória do sentimento e 0
9. Paradoxo que volta a tematizar em outras ocasiões, como na discussão do integralismo brasileiro, da burguesia paulista ou do golpe militar de 1964. 
sentimento da memória trabalham juntos com a memória do pensamento e o pensamento da memória, buscando integrar coração e mente para melhor entender os homens nas suas contradições e a vida de uma frágil mulher forte que representa e reafirma na coerência de suas incoerências os sonhos de justiça e bem- estar da e para a H umanidade.

\section{Referências Bibliográficas}

Alves de Seixas, Jacy. (2001), "Percursos de memórias em terras de história: problemáticas atuais". In: BR ESCIAN I, Stella \& N AXAR A, M árcia (orgs.). M emória/ (res)sentimento: indagaçoes sobre uma questão sensível, C ampinas, Editora da U nicamp.

An SART, Pierre. (2001), “H istória e memória dos ressentimentos”. In: Br ESCIAN I, M aria Stella

\& N AXAR A, M árcia (orgs.). M emória/ (res)sentimento: indagações sobre uma questão sensível, Campinas, Editora da U nicamp.

BAR BO SA, João Alexandre. (1986), “A trajetória de um crítico”. L íngua e L iteratura, 15: 95-104, São Paulo, FFLCH - USP.

BrescianI, Stella \& N AXAR A, M árcia (orgs.). (2001), M emória/ (res)sentimento: indagações sobre uma questão sensível. C ampinas, Editora da U nicamp.

C An DId o, Antonio. (1959), A formação da literatura brasileira. São Paulo, M artins. . (1959), 0 observador literário. São Paulo, Conselho Estadual de Cultura. . (1970), V ários escritos. São Paulo, D uas C idades. . (1980), Teresina etc R io de Janeiro, Paz eTerra. . (1987), A educação pela noite. São Paulo, Ática. . (1993), R ecortes. São Paulo, Companhia das Letras. . (2002), U m funcionário da monarquia: ensaio sobre o segundo escalão. R io de Janeiro, 0 uro sobre Azul.

Galvão, Walnice N ogueira. (2000), “A primeira paisana”. D. O. Leitura, 18 (9) (encarte 500 anos de $B$ rasil).

Galvão, Walnice N ogueira \& Lafer, C elso. (1981), "Teresina - e muito mais". In: Galvão, Walnice. $G$ atos de outro saco, São Paulo, B rasiliense, pp. 167-170.

M ou R A, M urilo M arcondes de. (1993), “C ircunstância e intersecções”. N ovos E studos (C ebrap), 36: 33-38, jul.

Pesavento, Sandra; Lenhardt; Chiappinı, Ligia \& A guiar, Flávio. (2001), É rico Veríssimo: 0 romance da história. São Paulo, N ova Alexandria.

Prado, Antonio Arnoni. (1992), "Anotador à margem". In: D IIn CAO, M aria Ângela \& Scarabôtolo, Eloísa Farra. D entro do texto, dentro da vida, São Paulo, Companhia das Letras/ Instituto M oreira Salles. . (1999), "Significação de recortes”. In: A guiar , Flávio (org.). A ntonio C andido: pensamento e militância, São Paulo, H umanitas/Fundação Perseu das Letras/Instituto M oreira Salles, pp. 135-141. 


\title{
Resumo
}

A nálise de Teresina etc., como exemplar de retratos escritos por Antonio Candido, que transcendem o particular e acabam fazendo o retrato de uma época, afirmando ideais éticos, políticos e estéticos e configurando, discretamente, não sem certo distanciamento irônico, um interessante auto-retrato. M emória e história, real idade e ficção, razão e sensi bilidade, crítica e compreensão são elementos que se tecem com arte, num texto muito atual, pelo tema e pela metodologia.

Palavras-chave: Antonio C andido; M emória; H istória; Ficção; A narquismo; Socialismo.

\begin{abstract}
Teresina etc as an example of the written portraits by Antonio Candido, that transcend the private and end up depicting an epoch, stating ethical, political and aesthetic ideals and configuring, discretely but not without a certain ironic distance, an interesting self-portrait. Memory and history, reality and fiction, sense and sensibility, critique and understanding woven with art.
\end{abstract}

Key words: Antonio C andido; M emory; H istory; Fiction; A narchism; Socialism.

LigiaC hiappni é professora titular da Cátedra de Brasilianística no Ins tituto Latinoamericano da U niversidade Livre de Berlim e ex-professora deTeoria Literária e Literatura Comparada na U niversidade de São Paulo, onde ainda orienta teses. Dos livros e artigos publicados, o maisrecente é a coletânea que organizou: L iteratura e aultura no Brasil: identidades e fronteiras (com M aria Stella Bresciani, 2002). 